\title{
Ceramics from Municipal Waste Incinerator Bottom Ash and Wasted Clay for Sensible Heat Storage at High Temperature
}

\author{
Nicolas Lopez Ferber ${ }^{1,2,3} \cdot{\text { Doan Pham } \text { Minh }^{2} \cdot \text { Q. Falcoz }}^{1} \cdot$ A. Meffre ${ }^{3} \cdot$ N. Tessier-Doyen ${ }^{4} \cdot$ A. Nzihou $^{2} \cdot$ V. Goetz $^{1}$
}

\begin{abstract}
Although work has been done to understand the sintering behavior and properties of Municipal Waste Incinerator Bottom Ashes to produce sintered (Bethanis et al. in Ceram Int 28:881-886, 2002; Cheeseman et al. in Resour Conserv Recycl 43:147-162, 2005; Bourtsalas et al. in Waste Manag 45:217-225, 2014; Taurino et al. in J Eur. Ceram Soc 37:323-331, 2017) or sinter-crystallized (Schabbach et al. in J Non Cryst Solids 357:10-17, 2011; Barbieri et al. in J Non Cryst Solids 354:521-528, 2008) ceramics, most of the trials reported in the literature focuses on the use of extensively milled bottom ashes powders (particle size around 1-50 $\mu \mathrm{m}$ ), using processes that might not be easily transferable to industrial production at reasonable cost, and producing small cylinders with uniaxial compression technique on powders. This paper summarizes the development process of an extruded ceramic material made of gross-milled bottom ashes and waste clay, designed to be easily mass-produced using production capacities available in the building bricks industry, to be used as a high-temperature thermal energy storage material, which represents an alternative to the petrurgic ceramic previously developed for this application (Py et al. in J Sol Energy Eng 133:031008, 2011; Kere et al. in Int Conf Eng Waste Biomass Valoris, Porto, 2012; Py et al. in Stockage de l' énergie: énergie thermique, stockage thermique haute température). Post-treated incinerator bottom ashes from a commercial incinerator has been collected, characterized and processed to form ceramic materials, using clay as a binder. Ashes were milled, dried, and mixed with various amounts of an illitic clay (produced as washing mud by a quartz quarry) prior to extrusion (cylindrical pellet) and firing at different temperatures, ranging from 1100 to $1120{ }^{\circ} \mathrm{C}$. The sintered samples have been characterized in terms of density, mechanical strength, thermal capacity and thermal conductivity. Their mineral structure has also been studied. This work follows a study on the feasibility about the production of MWIBA based slabs with uniaxial compaction, and can be seen as an improvement regarding the shaping of the green bodies, more compatible with thermocline thermal energy storage process. The resulting sintered ceramics exhibit interesting properties such as relatively high mechanical resistance and low thermal conductivity, along with moderate density. These properties allow envisioning the use as filler material for thermocline thermal storage systems, especially considering the simplicity of the production process, relying on dry gross milling (jaw-mill), and firing at a temperature reachable within the building bricks and tiles industry. Production of adequate pieces to be used as thermal storage media seems however more relevant, the small size limiting the impact of sintering heterogeneities (formation of black bodies due to high content in fluxing agents like sodium and potassium).
\end{abstract}

Keywords Thermal energy storage material $\cdot$ Waste-based ceramic $\cdot$ Sintering $\cdot$ Municipal waste incinerator bottom ashes

Nicolas Lopez Ferber

n.lopezferber@gmail.com

1 Laboratoire PROMES-CNRS UPR-8521, Université Perpignan Via Domitia, Rambla de la Thermodynamique, Tecnosud, 66100 Perpignan, France

2 Université de Toulouse, IMT Mines Albi, UMR CNRS 5302, Centre RAPSODEE, Campus Jarlard, 81013 Albi Cedex 9, France
3 SAS Eco-Tech Ceram, Espace Entreprises Méditerranée, Rue Edouard Belin, 66600 Rivesaltes, France

4 Institut de recherche sur les Céramiques, UMR CNRS 7315, Université de Limoges, 12 Rue Atlantis, 87068 Limoges Cedex, France 


\section{Statement of Novelty}

This work is focused on the assessment of the feasibility of extrusion for cylindrical pellets containing mainly municipal waste incinerator bottom ash, to be used as thermal energy storage material in thermocline systems. The cylindrical shape has been chosen as a compromise between the sphere, which offers interesting and challenging properties in packed beds, and the plate, which is only relevant in structured beds. The processes used in the design of the ceramic material has been chosen to be compatible with construction materials industry capabilities, to allow mass-production at low cost.

\section{Introduction}

Municipal waste incineration is a common technique for household wastes (usually high carbon content) treatment. It consists in the combustion of these wastes at high temperature $\left(900-1200{ }^{\circ} \mathrm{C}\right)$, therefore reducing their volume by up to $90 \%$, decreasing land use compared to direct household wastes landfilling [10]. Most of the incinerators recover the heat generated to produce industrial steam or electricity. Considered as renewable energy, it represents around 1.7 $\mathrm{TWh}_{\mathrm{e}}$ in 2015 in France (comparable to biogas, or solid biomass) [11].

The main solid byproduct of incineration is Municipal Waste Incineration Bottom Ash (MWIBA), representing around $25 \%$ of the total input weight, the others being fly ash, air pollution control residues and dusts [12]. This is a quite complex material, with composition varying in time and space, as revealed by the discrepancies in composition of MWIBA samples in the literature (Table 1).

The bottom ash is typically classified as "non-dangerous waste" and landfilled, although some countries extensively use it as a filler for road sub-base construction. For example, around $80 \%$ of the $3 \mathrm{Mt}$ of bottom ashes generated yearly in France are used as road sub-base filler after several treatment steps involving milling, sieving, ferrous metals removal (magnetic separation) and non-ferrous metals removal (Eddy currents), and ageing (stabilization of leaching properties through calcium oxide carbonation) [17].

Even though most of the bottom ash is successfully reused in France, this is not the case among other European countries, so most of the $12 \mathrm{Mt}$ produced annually is landfilled [10]. Being mostly a mixture of mineral compounds, namely alumina, hematite, silica and alkali oxides in the form of a heterogeneous gravel, it can be compatible with ceramic materials production $[1,18]$, which can represent a new valorization path, instead of road subbase filler production, providing new feedstock for ceramic industry and saving resources and environmental impacts related to clay and sand extraction. Another interesting application calls for high temperature storage systems, using ceramics as sensible thermal storage material in thermocline packed bed or structured bed systems [19]. Some authors worked on such waste-based ceramics, using molten asbestos containing wastes [7], metallurgical slags [20] or coal fly ash [21], mostly using the petrurgic method implying casting and controlled cooling from molten state, a technique that is not considered as easily transferable to

Table 1 Composition of several MWIBA samples studied in the literature

\begin{tabular}{|c|c|c|c|c|c|c|c|c|}
\hline References & Vu et al. [13] & Bethanis et al. [1] & $\begin{array}{l}\text { Barbieri } \\
\text { et al. [6] }\end{array}$ & $\begin{array}{l}\text { Schabbach et al. } \\
\text { [5] }\end{array}$ & Aloisi et al. [14] & $\begin{array}{l}\text { Appendino et al. } \\
{[15]}\end{array}$ & $\begin{array}{l}\text { Bourtsa- } \\
\text { las et al. } \\
{[3]}\end{array}$ & $\begin{array}{l}\text { Barbieri } \\
\text { et al. } \\
{[16]}\end{array}$ \\
\hline Analysis & ICP AES & ICP AES & $\mathrm{XRF}$ & $\mathrm{ICP}$ & $\mathrm{XRF}$ & AAS & XRD & ICP \\
\hline \multicolumn{9}{|c|}{ Compound (\% dry weight) } \\
\hline $\mathrm{SiO}_{2}$ & 31.1 & $40.1-42.1$ & 46.7 & $30.3-35.1$ & 40.9 & $42.5-40.9$ & 30.4 & 45.1 \\
\hline $\mathrm{CaO}$ & 10.0 & $18.4-20.0$ & 26.3 & $23.1-26.1$ & 12.2 & $16.4-12.2$ & 26.8 & 18.8 \\
\hline $\mathrm{Al}_{2} \mathrm{O}_{3}$ & 2.57 & $9.92-14.2$ & 6.86 & $13.0-13.6$ & 13.6 & $17.6-13.6$ & 11.5 & 9.73 \\
\hline $\mathrm{Na}_{2} \mathrm{O}$ & 2.10 & $2.60-2.75$ & 4.62 & $1.94-2.44$ & 10.9 & $12.9-10.9$ & 3.32 & 4.64 \\
\hline $\mathrm{MgO}$ & 0.28 & $1.79-1.90$ & 2.22 & $2.83-3.73$ & 3.1 & $2.3-3.1$ & 2.64 & 2.20 \\
\hline $\mathrm{Fe}_{2} \mathrm{O}_{3}$ & 4.36 & $6.20-6.60$ & 4.69 & $10.0-11.5$ & 5.7 & $5.7-5.7$ & 13.1 & 3.84 \\
\hline $\mathrm{TiO}_{2}$ & 0.83 & $1.00-1.14$ & 0.77 & $1.07-1.71$ & 1.2 & $2.5-1.2$ & 1.39 & 0.93 \\
\hline $\mathrm{P}_{2} \mathrm{O}_{5}$ & 2.07 & $1.34-1.44$ & - & $1.96-1.90$ & - & - & 2.18 & - \\
\hline $\mathrm{SO}_{3}$ & 0.60 & - & 2.18 & - & - & - & 3.05 & - \\
\hline $\mathrm{K}_{2} \mathrm{O}$ & 0.86 & $0.86-0.92$ & 0.89 & $0.94-1.45$ & 1.8 & $1.8-1.8$ & 1.33 & 1,29 \\
\hline $\mathrm{CrO}_{\mathrm{x}}$ & 0.90 & - & - & - & - & - & - & - \\
\hline $\mathrm{MnO}$ & - & 0.08 & - & $0.18-0.17$ & - & $0.1-0.1$ & 0.31 & - \\
\hline LOI (\%drwt) & 5.21 & - & 11 & - & - & - & - & - \\
\hline
\end{tabular}


industry and mass-production. Sintering alumino-silicate industrial sub products appears to be preferable, due to the higher production capabilities of the sintering production pathway [22].

Research projects have been carried out regarding the sintering behavior of MWIBA, but being focused on sintering or crystallization behavior rather than production considerations; the processes and materials they proposed might not be suited for mass-production at reasonable cost (micronic wet-milling [1], compression for uniaxial shaping, casting at molten state or sinter-crystallization from a glass [5], valuable additives like high-grade kaolin [23] and so on).

In this work another process has been developed for the production of a $100 \%$ waste-based ceramic, using production protocols as simple and widely available as possible This process is based on the conventional extrusion technique, used in the ceramic building bricks industry. The ceramics obtained should exhibit properties suitable for sensible heat thermal storage up to $1000{ }^{\circ} \mathrm{C}$, under air. Hence, the desired properties of the resulting material are as follows:

- Maximal volumetric thermal capacity $(\rho \times \mathrm{Cp})$, implying maximizing densification during sintering. This is especially important for thermal storage applications, since it would increase thermal storage capacity per unit volume.

- Regarding thermocline packed bed air/ceramic storage systems, a high thermal conductivity is beneficial for storage behavior, ensuring that the Biot number is significantly lower than 1 , but this could also be achieved by decreasing the size of the particles, at the cost of increased pressure drop.

- Satisfying mechanical strength, measured as compressive strength (>20 MPa). A high compressive strength for a thermal storage material will allow increasing the height of the packed bed without damaging the pieces.

- Thermal stability over a large range of temperatures that can be encountered in thermal energy storage (up to $800-1000^{\circ} \mathrm{C}$ ), under air

- Satisfying thermomechanical behavior, measured as the Coefficient of Thermal Expansion (CTE). This CTE should be as low as possible, or at least present predictable variations with temperature, to avoid increasing mechanical stress during use.

The strategy chosen focused on the simplicity of the production process, because the amount of materials required for sensible heat storage technology can be important, in both the sectors of industrial energetic efficiency and concentrated solar power techniques [24], implying that the developed material should be compatible with mass-production at low cost.

\section{Materials and Methods}

\section{Materials Processing}

\section{Sampling}

$450 \mathrm{~kg}$ of an aged MWIBA have been collected in the maturation platform of a commercial incinerator in southern France using coning and quartering method as defined by the UIPAC [25], after post-treatment process (magnetic removal of ferrous and non-ferrous metals, ageing). The bottom ashes complied with the requirements for homologation as "MWIBA gravel 0-40 mm" as defined in the Setra guide for MWIBA management [17]. Like most MWIBA, it consists in a mixture of ashes, sand, glassy material, metallic and ceramic fragments and residual unburnt organic compounds [26].

\section{Milling}

The particle size distribution (PSD) of as-collected MWIBA was not compatible with shaping and firing protocols, so the MWIBA had to be milled. The goal being to assess the feasibility of MWIBA ceramics production in building bricks and tile industry, we disregarded extensive wet milling. These techniques, although relevant to produce thin and homogeneous powders, seemed too complicated and not easily transferable to industrial settings, so an easier method has been favored. MWIBA has been dried at $105{ }^{\circ} \mathrm{C}$ for 1 day, before being milled with a tungsten jaw mill. MWIBA has been milled with three passes inside the jaw mill, the jaw being enclosed between each pass, from a $10 \mathrm{~mm}$ gap to a $1 \mathrm{~mm}$ gap. The powder obtained has then be sieved at $500 \mu \mathrm{m}$. The passing fraction has then been used for the trials. Milling several hundred grams with this technique requires approximately $45 \mathrm{~s}$, and can be upscaled reasonably easily due to the great availability of jaw mills in the mineral industries.

\section{Shaping}

Shaping the green bodies before firing being an important step for any applications, adding a binding agent to the MWIBA was considered, in order to give the mixture high enough plasticity to undergo extrusion. Thus, a wasted clay was used as binder. This clay is a by-product of a quartz producing company located in southern France, with a generation rate of $100 \mathrm{t} /$ day. It is a fine powder $\left(\mathrm{d}_{50}=16 \mu \mathrm{m}\right)$ of an illitic clay, obtained by flocculation/decantation of a washing mud. For these trials, we used an extrusion device located in the CTMNC technology transfer facility, which is a scaled-down model of an industrial extrusion device 
(single screw, two stages, equipped with a void pump), with a conical end-piece with an opening of $20 \mathrm{~mm}$ wide, to produce $40 \mathrm{~mm}$ long cylinders. The added clay represents 20 , 30 or $40 \%$ of the paste dry weight. Hence, this paper will mostly focus on the influence of the clay to bottom ash ratio in the formulation and firing temperature on the resulting properties of the sintered samples.

\section{Firing}

After being dried at 105 for $6 \mathrm{~h}$, green bodies have been fired in electrical furnaces, with a heating rate of $5^{\circ} \mathrm{C} / \mathrm{min}$ from room temperature to $500{ }^{\circ} \mathrm{C}$, then $2{ }^{\circ} \mathrm{C} / \mathrm{min}$ from $500{ }^{\circ} \mathrm{C}$ to the maximum temperature, with isothermal firing duration varying from 1 to $4 \mathrm{~h}$ depending of the samples. The furnaces are not equipped with an active cooling system, implying cooling durations of about $10 \mathrm{~h}$. The different stages of the process are illustrated by Fig. 1 .

It is worth noting that, although formulations with 20 and $30 \mathrm{wt} \%$ clay required plasticizer (Zschimmer \& Schwartz, Zusoplast C39) to form a plastic paste suitable for extrusion, $40 \mathrm{wt} \%$ clay formulation only required water (Table 2).

\section{Raw Material Characterization}

Chemical composition of the raw materials has been characterized with ICP-AES. Samples have been milled and sieved at $40 \mu \mathrm{m}$. The clay and the MWIBA have been dissolved into a mix of nitric and fluorhydric acid into a micro-wave oven (Anton Paar) under heat. The samples have been heated up to $240{ }^{\circ} \mathrm{C}$ and 60 bars in $10 \mathrm{~min}$, with $40 \mathrm{~min}$ dwell time. After total dissolution, the sample have been characterized using a Perkin-Elmer Optima 8300 ICP device.

PSD of the powders has been measured using a Malvern Mastersizer 3000 granulometer, on carefully dried powders, for a particle size range of $0-1000 \mu \mathrm{m}$.

Loss On Ignition has been measured for the raw powders by comparing the mass of a sample of powder, before and after being heated up to $1000^{\circ} \mathrm{C}$ for $2 \mathrm{~h}$. This characteristic of the powders also had been confirmed with TG-DSC (Labsys Evo from Setaram, with $3 \mathrm{~L} / \mathrm{h}$ air, and a heating rate of $5{ }^{\circ} \mathrm{C} / \mathrm{min}$ from room temperature to $1100{ }^{\circ} \mathrm{C}$ ).

The mineral phases present in the raw materials have been identified with X-Ray Diffraction, using a Philips
Table 2 Formulation parameters of plastic paste

\begin{tabular}{llll}
\hline Formulation & $\begin{array}{l}\text { Clay [\%dry- } \\
\text { weight] }\end{array}$ & $\begin{array}{l}\text { Plasticizer [\%dry- } \\
\text { weight] }\end{array}$ & $\begin{array}{l}\text { Water } \\
{[\% \text { total }} \\
\text { weight }]\end{array}$ \\
\hline $20 \% \mathrm{~ms}-1$ & 20 & 0.29 & 38 \\
$30 \% \mathrm{~ms}-1$ & 30 & 0.18 & 40 \\
$40 \% \mathrm{~ms}-0$ & 40 & 0.00 & 28 \\
$40 \% \mathrm{~ms}-1$ & 40 & 0.72 & 29 \\
\hline
\end{tabular}

PANalytical X'pert Pro MPD device (copper emitter, $\mathrm{K}_{\alpha}=1543 \AA$ ), from $2 \theta=10^{\circ}$ to $2 \theta=80^{\circ}$.

\section{Characterization of the Sintered Samples}

The goal being to assess the potential of these ceramics for thermal storage at high temperature, the main properties investigated are as follows:

- Volumic mass, expressed in $\mathrm{kg} / \mathrm{m}^{3}$ or in relative density, has been measured with the Archimede method, comparing dry and immersed sample apparent weight.

- Thermal capacity, expressed in $\mathrm{J} /(\mathrm{g} \mathrm{K})$, has been measured by a modular DSC (Q200 from TA), with a $50 \mathrm{~mL} /$ min nitrogen flow, at room temperature and $390{ }^{\circ} \mathrm{C}$, $390{ }^{\circ} \mathrm{C}$ being close to the average temperature of use. Four samples have been also characterized by NETZSCH Applications Laboratory, using a DSC 404 F1 Pegasus differential scanning calorimeter from room temperature to $1000{ }^{\circ} \mathrm{C}$, using a $10 \mathrm{~K} / \mathrm{min}$ heating ramp, under air.

- Thermal diffusivity has been measured with a Laser Flash Analysis device from Netzsch (LFA 457) from room temperature to $1000{ }^{\circ} \mathrm{C}$, with a heating ramp of $20 \% \mathrm{~min}$. The knowledge of the variations of specific heat with temperature allowed calculating the thermal conductivity of these samples.

- Thermal stability in the temperature range of $0-1000{ }^{\circ} \mathrm{C}$ is of highest importance. The behavior of the sintered samples under thermal cycling has been investigated with DTA and TMA (Setsys device from Setaram). The coefficient of thermal expansion should also been as low as possible, or at least predictable so to avoid generating strains inside a bed of these materials.
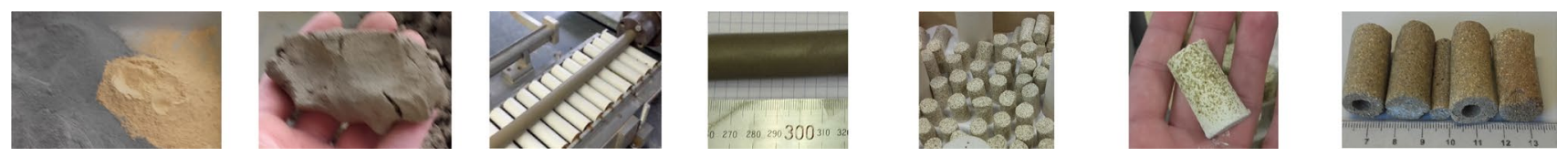

Fig. 1 Stages of the production process. From left to right: dry powders before mixing, paste formation, extrusion, extruded green body, fired batch and individual piece, fired cylinders prepared for analysis 
- Compressive strength of the ceramics will set the limit to the system's size. Therefore, high compressive strength can be beneficial to this material. It has been measured by submitting samples to an uniaxial force, using a hydraulic press and increasing the load until sample's rupture, on small cylindrical samples.

To assess the potential of optimization of these materials, they also have been characterized in terms of water absorption, related to open porosity. Samples exhibiting higher values of water absorption might be indicating lower sintering quality. XRD allowed also to identify the main mineral phases inside the sintered bodies, as well as to quantify their respective proportions, using a D8 Advance Bruker XRD

Table 3 Chemical composition of clay and MWIBA (ICP-AES)

\begin{tabular}{lll}
\hline Compound [wt\%] & Clay & MWIBA \\
\hline $\mathrm{Al}_{2} \mathrm{O}_{3}$ & 27.1 & 6.2 \\
$\mathrm{SiO}_{2}$ & 53.7 & 58.7 \\
$\mathrm{CaO}$ & 2.3 & 5.3 \\
$\mathrm{Fe}_{2} \mathrm{O}_{3}$ & 5.9 & 6.0 \\
$\mathrm{~K}_{2} \mathrm{O}$ & 5.2 & 1.8 \\
$\mathrm{MgO}$ & - & 2.1 \\
$\mathrm{Na}_{2} \mathrm{O}$ & 0.8 & 7.7 \\
$\mathrm{SO}_{\mathrm{x}}$ & - & 1.0 \\
$\mathrm{LOI}\left(1000{ }^{\circ} \mathrm{C}\right)[\mathrm{wt} \%]$ & 4.9 & 5.2 \\
$\mathrm{~d}_{50}[\mu \mathrm{m}]$ & 16 & 166 (milled) \\
\hline
\end{tabular}

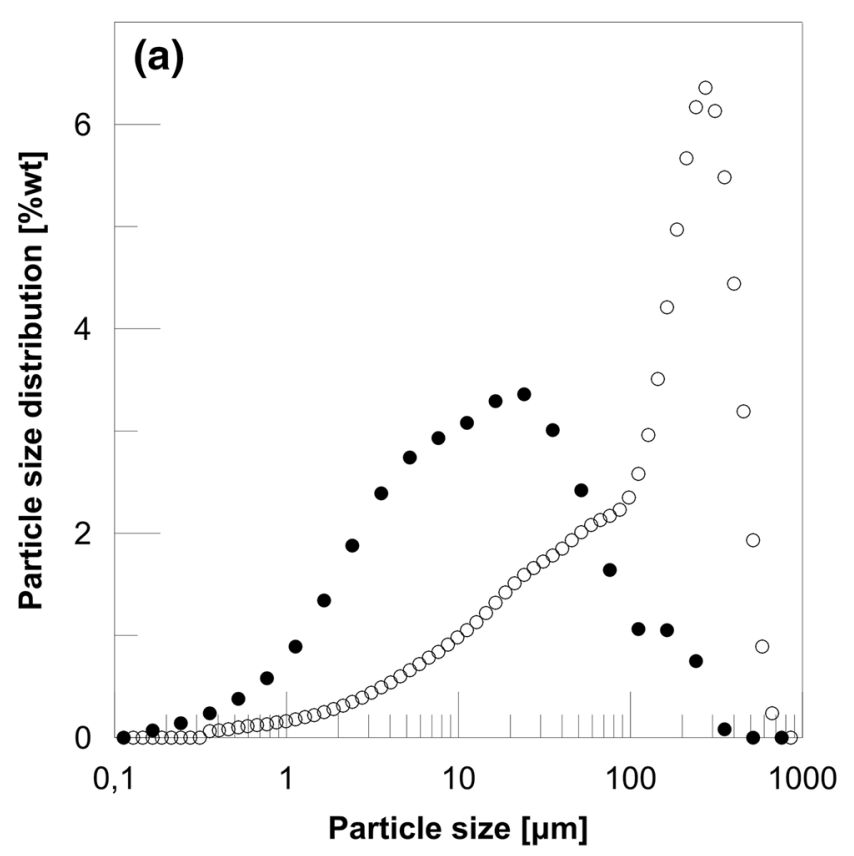

device $\left(5^{\circ}<2 \theta<80^{\circ}\right)$, coupled with a LynxEye device and using a Rietveld protocol.

\section{Results}

\section{Raw Material Characterization}

\section{Composition and Particle Size Distribution}

Both the clay and MWIBA are mostly composed of silica. The clay has higher proportion of alumina and potassium oxides, whereas the MWIBA contains more sodium oxides (Table 3). These compounds are known for their relevance as fluxing agents, and so might facilitate sintering.

The composition is on part with other MWIBA studied in the scientific literature, although this MWIBA in particular is richer in silicon oxide than most of the samples studied in the literature. Its "lower than usual" content in alumina could be explained by differences of in waste-sorting policies.

The clay was not milled, and exhibit a Gaussian-like particle size distribution, centered on its $\mathrm{d}_{50}$ of $16 \mu \mathrm{m}$. The milled MWIBA exhibits a completely different reparation of particle size, with an over-representation of coarse particles $(>100 \mu \mathrm{m})$, mixed with smaller particles. The $\mathrm{d}_{50}$ of the milled MWIBA is $166 \mu \mathrm{m}$, superior of that's of the clay by an order of magnitude (Fig. 2).

This situation, where one of the powder is much coarser and with a sharper distribution and the other one is smaller

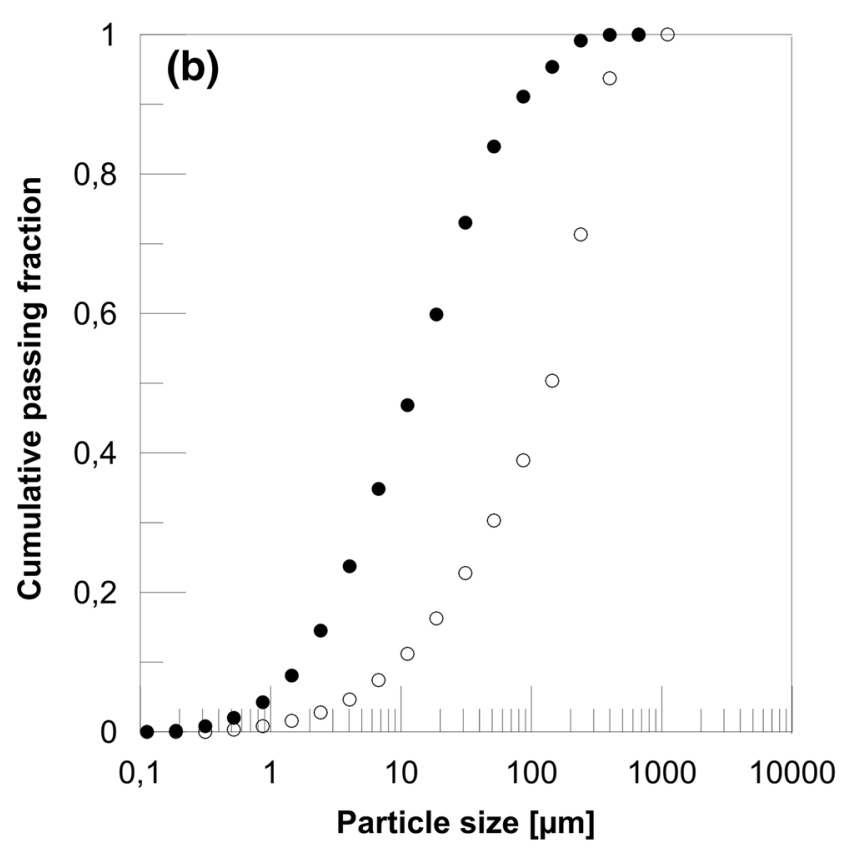

Fig. 2 a Particle size distribution of milled MWIBA (open circle) and clay (filled circle), b cumulative passing fractions of milled MWIBA (open circle) and clay (filled circle) 
with a broader PSD is favorable to maximal mixture quality and compacity of the green bodies, the smaller particles being able to fill the porosity between the coarser ones. A difference of particle size of around 1:10 is usually described as relevant for increasing green bodies compacity [27]. The two powders comply with this requirement (Fig. 2), increasing the maximal compacity and homogeneity achievable for the green bodies.

\section{Raw Materials Mineralogy}

Both clay and MWIBA powders have been characterized in terms of mineral composition. The clay exhibits typical illitic clay phases, such as illite and kaolinite, associated with quartz and K-feldspath, (presumably microcline). The MWIBA powder exhibits typical quartz and calcite phases, associated with wollastonite and pyrite (Fig. 3). Pyrite is not usually reported in the literature as being present in bottom ashes, the iron being mostly present as oxide (hematite).

\section{Raw Materials Thermal Behavior}

MWIBA have been milled in a tungsten carbide ring mill and sieved at $50 \mu \mathrm{m}$ to obtain a fine powder suitable for DSC-TG analysis. This sample exhibits a thermal behavior similar to those studied in literature (Fig. 4), namely:

- An endothermic phase between room temperature and around $250{ }^{\circ} \mathrm{C}$, associated with mass loss, which is most

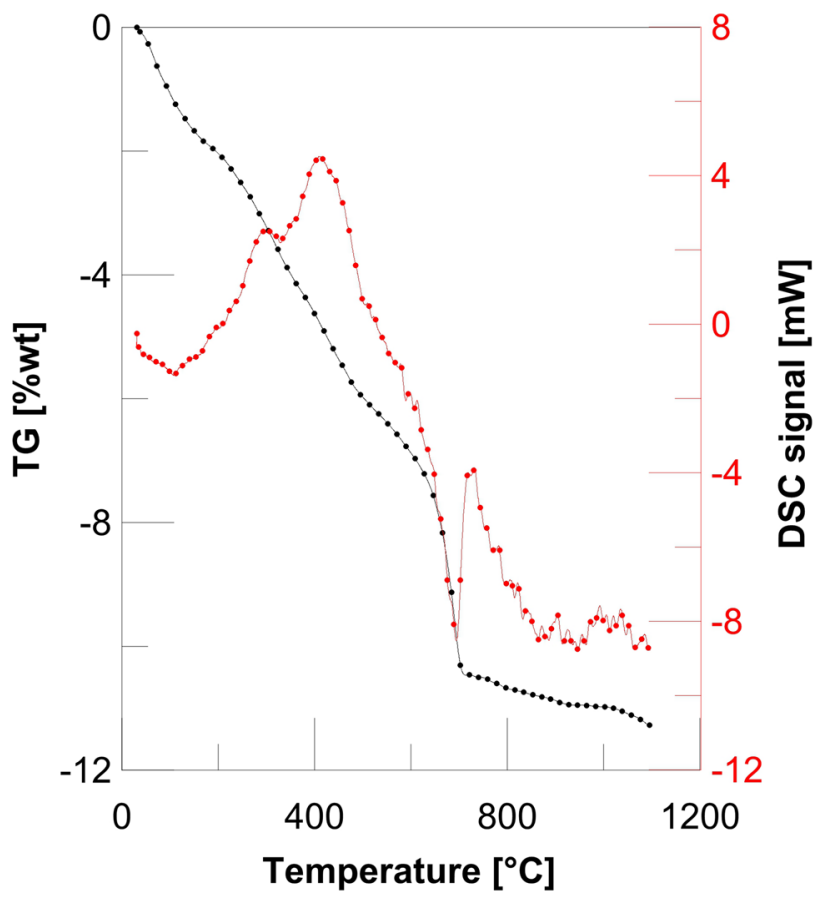

Fig. 4 Thermal behaviour (red coloured circle) and weight loss (black coloured circle) of MWIBA. (Color figure online)

often attributed to the vaporization of residual, bound and hydration water.

- An exothermic phase between 300 and $500{ }^{\circ} \mathrm{C}$, associated with mass loss. These peaks are presumably due to the

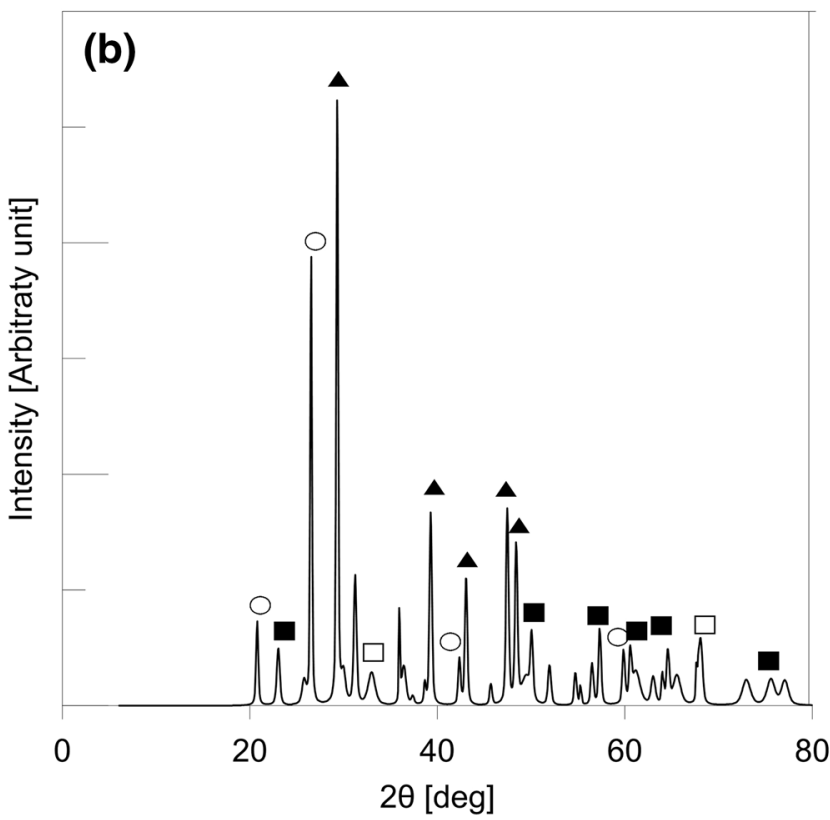

Fig. 3 a XRD diffractogram of raw clay. filled circle Illite, hollow circle Quartz, filled diamond Kaolinite, open diamond K-Feldspath, b XRD diffractogram of raw MWIBA. Filled circle: quartz, filled triangle: calcite, filled square: Wollastonite, filled square: pyrite 
combustion of unburnt organic matter and the release of occluded gases [1].

- A sharp endothermic peak around $700{ }^{\circ} \mathrm{C}$, associated with a sharp weight loss. This is typically associated with calcite decarbonation $\left(\mathrm{CaCO}_{3} \longrightarrow \mathrm{CaO}+\mathrm{CO}_{2}\right)$. The usual temperature for calcite decarbonation is around $900{ }^{\circ} \mathrm{C}$, but this phenomenon appears to occur at lower temperature when calcite is found in MWIBA [18, 28, 29]

- Above $1000{ }^{\circ} \mathrm{C}$, the thermal behavior becomes chaotic due to simultaneous melting and crystallization of the different phases as well as specific heat variations. At high temperature, some weight losses can be attributed to alkali metal sulfates dissociation [1].

The weight loss is higher than noticed during sintering tests, which is presumably due to concentration of volatile organic matter into the small-sized particles.

The clay exhibits very common thermal behaviour, with an endothermic peak around $100-150{ }^{\circ} \mathrm{C}$ associated with bounded water removal, followed by a sharp weight loss between 450 and $600{ }^{\circ} \mathrm{C}$ associated to kaolinite deshydroxylation and a $980{ }^{\circ} \mathrm{C}$ exothermic peak related to structural transformation of illite to mullite. This clay starts vitrifying at $1250{ }^{\circ} \mathrm{C}$, a temperature where it reaches its maximum shrinkage (7\%) (information provided by supplier).

\section{Sintered Samples Properties}

All the samples will be designated as follows: XXXX-YY$\mathrm{Z}-\mathrm{H}$, with $\mathrm{XXXX}$ the firing temperature $\left({ }^{\circ} \mathrm{C}\right), \mathrm{YY}$ the clay content ( $\%$ dry weight), $\mathrm{Z}$ the dwell time (h) and $\mathrm{H}$ the use of plasticizer additive ( 0 if no plasticizer is used, 1 if it is). Due to the considerable number of samples produced, only the ones considered interesting (due to their superior properties or interesting to compare with others) have been characterized further than volumic mass (Table 4).

\section{Volumic Mass and Water Absorption}

Fired density of samples have been measured with Archimede's method. Water absorption has been measured repeatedly on several samples by comparing dry and wet mass. Both are illustrated on Fig. 5. It appears that the fired density variations between samples were minor, all of them exhibiting values between 1.75 and $1.91 \mathrm{~g} / \mathrm{cm}^{3}$. Depending on the composition, the maximum density was obtained at different

Table 4 Samples selected for further characterization

\begin{tabular}{lll}
\hline $1100-20-4-1$ & $1100-30-4-1$ & $1100-40-4-0$ \\
$1115-20-4-1$ & $1115-30-4-1$ & $1115-40-4-0$ \\
$1120-20-1-1$ & $1120-30-1-1$ & $1120-40-4-1$ \\
\hline
\end{tabular}

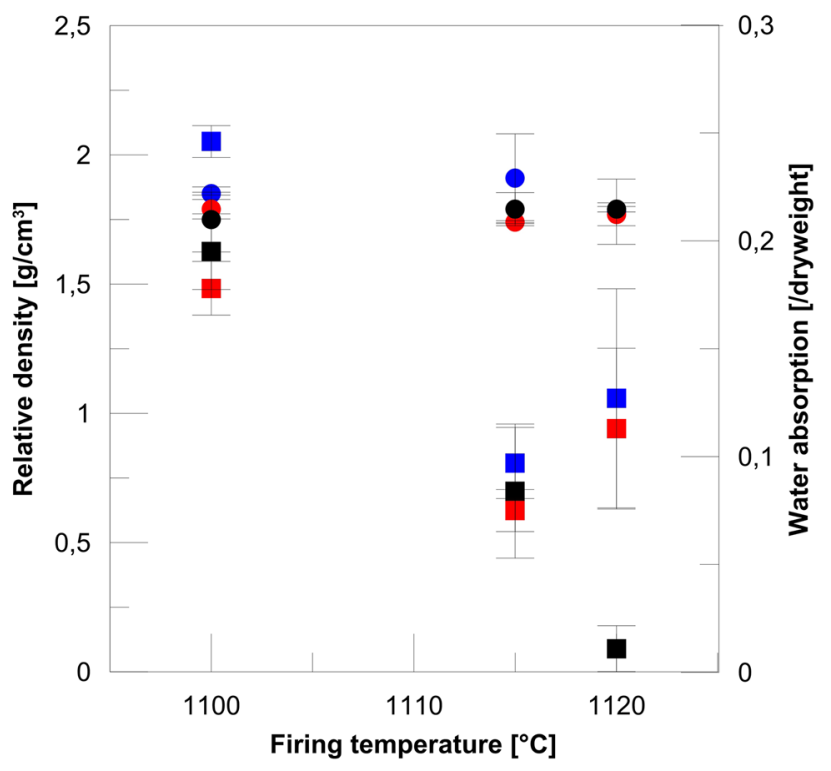

Fig. 5 Relative density (dots) and water absorption (squares), for each formulation (20, 30, 40\% clay), as a function of firing temperature

temperatures. For example, with $20 \mathrm{wt} \%$ clay, the highest density was achieved for $\mathrm{T}_{\text {firing }}=1115^{\circ} \mathrm{C}$. There was no increase in density between samples fired at $1115^{\circ} \mathrm{C}$ and those fired at $1120^{\circ} \mathrm{C}$. This can be explained by the creation of black bodies, related to partial melting of the material, leading to closed porosity. Some authors mentioned also that the decomposition of sulfates compounds can occur in this temperature range, the production of gases limiting density. Water absorption varies widely between samples, the lowest values being reached by samples 1115-20-4-1, 1115-30-4-1 and 1120-40-4-1. Low water absorption is somehow related to higher densities, but the difference is quite low. Water absorption could be related to the sintering process, open and interconnected porosities being the first closed during firing [30], before overfiring and melting lead to new open pores formation, as water absorption is linked to open porosity and pore size distribution [31].

\section{Thermal Properties}

The volumetric thermal capacity is the product of volumic mass and specific heat. As previously mentioned, all samples exhibit relatively close volumetric mass, but the quite different thermal capacity per unit mass leads to significant differences in terms of volumetric thermal capacity, whether taken at room temperature or $390{ }^{\circ} \mathrm{C}$. Similar to the compressive strength, the samples containing $30 \mathrm{wt} \%$ clay and fired at $1115^{\circ} \mathrm{C}$ exhibited superior properties by a significant margin (Fig. 6). Thermal conductivity was in the typical range for ceramic-based materials, the highest being $1 \mathrm{~W} /(\mathrm{m} \mathrm{K})$ for the 1115-30 sample, at room temperature. 

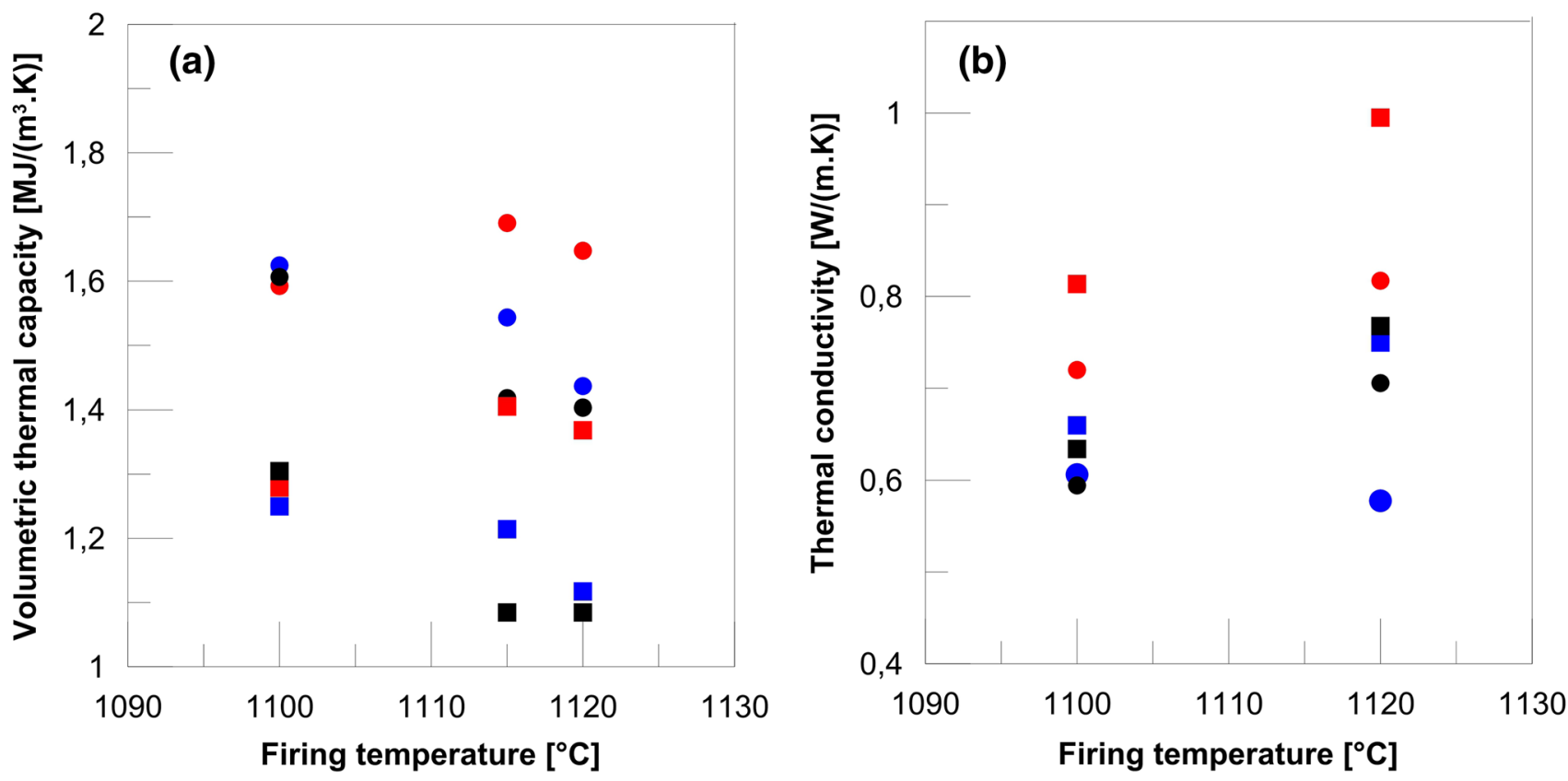

Fig. 6 a Volumetric thermal capacity and $\mathbf{b}$ thermal conductivity as a function of firing temperature, for $20 \%$ (blue coloured circle), $30 \%$ (red coloured circle) and $40 \%$ (black coloured circle) clay, at room temperature (squares) and $390{ }^{\circ} \mathrm{C}$ (dots). (Color figure online)

\section{Mechanical/Thermomechanical Properties}

For samples with the lower amount of clay, compressive strength increased from 10 to $28 \mathrm{MPa}$ when firing temperature increased from 1100 to $1115^{\circ} \mathrm{C}$. However, at higher temperature, the high melting tendency of the bottom ash led to a decrease in compressive strength. For the highest proportion of clay, compressive strength stayed stable between 1100 and $1115^{\circ} \mathrm{C}$, before slightly increasing at $1120{ }^{\circ} \mathrm{C}$. With $30 \%$ clay, compressive strength increased vastly in this temperature range, the increase being especially fast between 1115 and $1120^{\circ} \mathrm{C}$ firing temperatures (Fig. 7). The samples containing 30 and $40 \mathrm{wt} \%$ clay and fired at $1120{ }^{\circ} \mathrm{C}$ exhibited compressive strength superior to the $40 \mathrm{MPa}$ threshold, considered in the literature as a minimum requirement for heavy-duty construction materials [15, 32], although variability is especially high with the $40 \%$ clay formulation.

The samples' CTE has been measured using a TMA device, for all mentioned samples except 1115-40, which broke during the preparations for analysis.

The coefficient of thermal expansion (CTE) of samples is relatively low, and is lower for higher firing temperatures of the samples and for higher clay content. The CTE in the temperature range of $25-1000{ }^{\circ} \mathrm{C}$ is between 0.7 and $0.85 \%$, which are comparable to alumina (Fig. 8). No significant hysteresis was detected between the heating and the cooling phase, further confirming the stability of the samples. The smooth profile of these curves also indicate the absence or

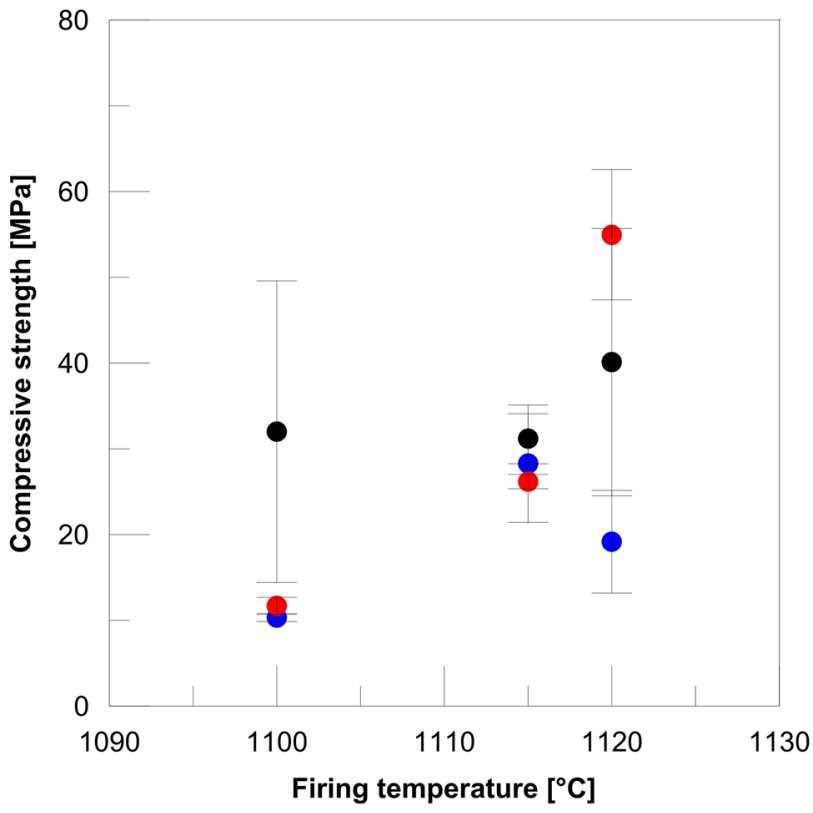

Fig. 7 Compressive strength as a function of firing temperatures, for $20 \%$ (blue coloured circle), 30\% (red coloured circle) and 40\% (black coloured circle) clay. (Color figure online)

weakness of thermally-induced mineral transformations that might have led to anomalies in CTE (the quartz-point being an example of this type of phenomenon). 

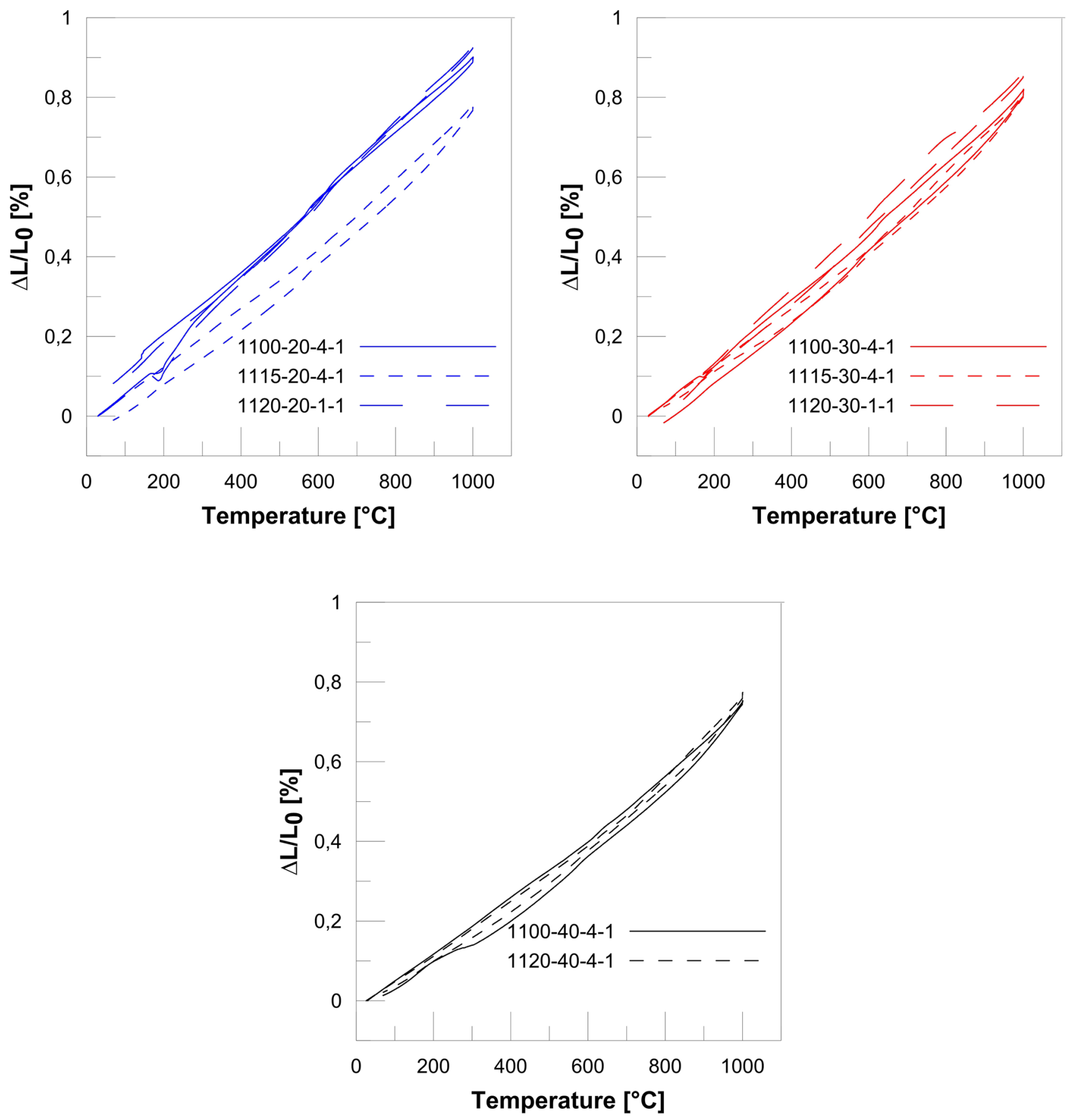

Fig. 8 Coefficient of thermal expansion as a function of temperature (heating and cooling) fired at 1100,1115 and $1120^{\circ} \mathrm{C}$

\section{Thermal Stability}

In a given air/ceramic thermocline storage system, TES material will be subjected to thermal cycling from ambient up to $1000{ }^{\circ} \mathrm{C}$, under air atmosphere. It should therefore be thermally stable between room temperature and $1000{ }^{\circ} \mathrm{C}$, regarding both mineralogy and thermal expansion aspects. Selected samples (1120-40 and 1100-40) have been thermally cycled 3 times from 30 to $1000{ }^{\circ} \mathrm{C}$ under air, with $10^{\circ} \mathrm{C} / \mathrm{min}$ heating ramp and $30 \mathrm{~min}$ isotherm in a TG-ATD device (TMA Setsys, from Setaram, TG-ATD Labsys from Setaram). Analysis revealed that the samples exhibited endothermic phenomena around $900{ }^{\circ} \mathrm{C}$, whether it occurs during the heating or the cooling phase (Fig. 9). These are not related to the melting of the material, and are not linked to weight losses. Therefore, it is more realistic to attribute them 

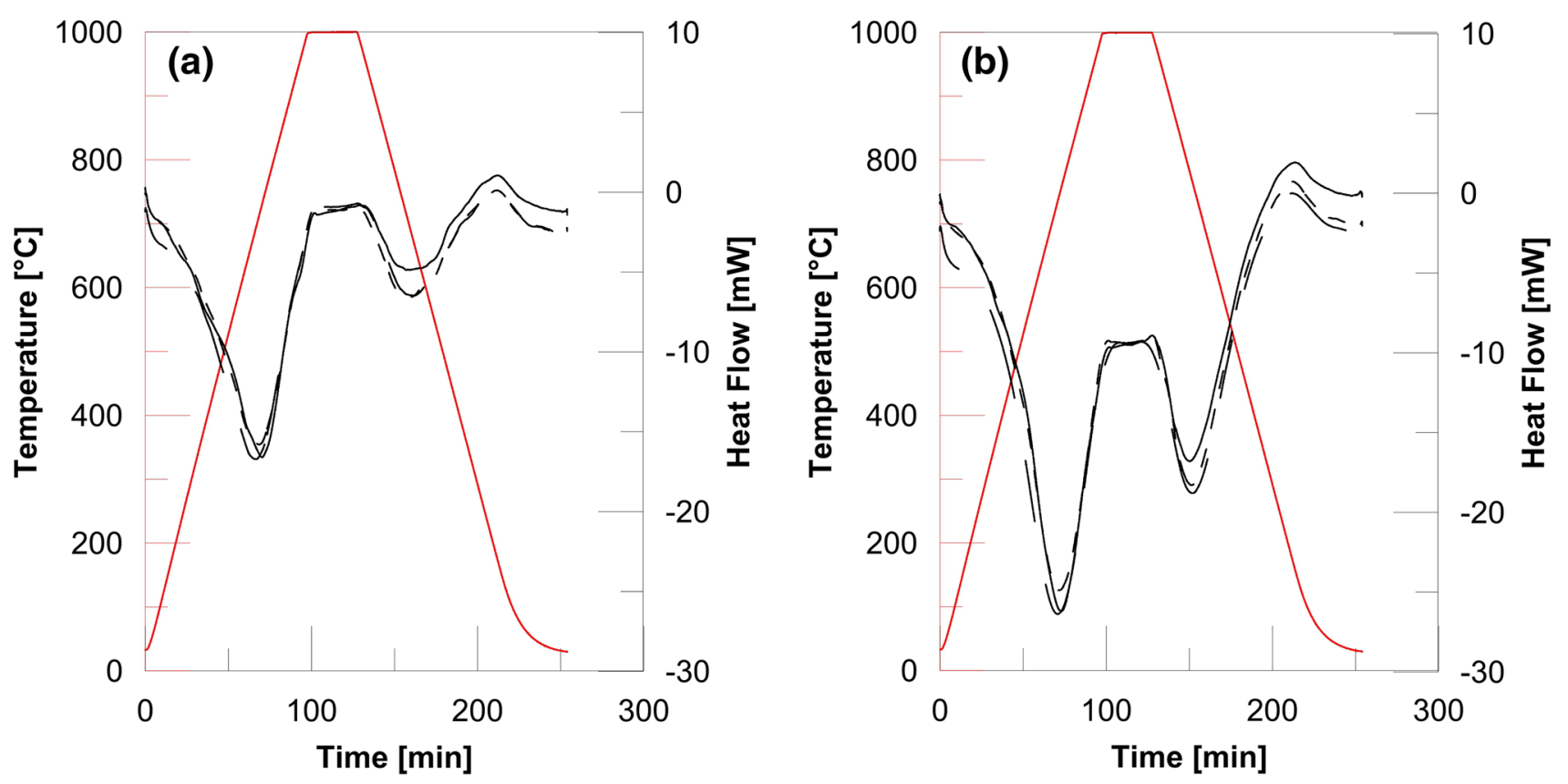

Fig. 9 Differential thermal analysis graphics for 3 cycles from 25 to $1000{ }^{\circ} \mathrm{C}$ : a $1100-40$ sample and b $1120-40$

to reversible mineralogical transformations or specific heat variations. Anyway, those behaviors are highly reproducible, and did not influence the coefficient of thermal expansion in this temperature range. Thus, the material can be considered stable enough in this temperature range.

\section{Mineralogy}

The XRD conducted on the 9 samples revealed the presence of the same mineral phases, although their relative proportions changed depending on formulation and firing temperature. There is a low-level noise, as well as much noise for angles less than $20^{\circ}$, indicating glassy/amorphous phases. Moreover, the sheer number of low-intensity peaks indicates a complex mineralogical matrix (Fig. 10).

The semi-quantitative analysis of relative proportion of phases has been conducted in an attempt to link particular macro-properties of the samples to the relative proportions of different phases. Five main mineral phases have been detected, identified and quantified, namely Wollastonite $\left(\mathrm{CaSiO}_{3}\right.$, Crystallography Open Database Number 96-9005779), Quartz ( $\mathrm{SiO}_{2} / \mathrm{Si}_{4} \mathrm{O}_{8}, \mathrm{COD}$ Numbers 01-078-1852/96900-6307), Albite ( $\mathrm{NaAlSi}_{3} \mathrm{O}_{8}$, COD Number 96-9001633), Augite [( $\mathrm{Si}, \mathrm{Al})_{2} \mathrm{O}_{6}, \mathrm{COD}$ Number 96-120-0007] and Clinoenstatite $\left(\mathrm{Mg}_{2} \mathrm{Si}_{2} \mathrm{O}_{6}, \mathrm{COD}\right.$ Number 96-900-2714) (Table 5).

First, it is noticeable that the proportions of Augite and Clinoenstatite were quite stable for all samples, notwithstanding firing temperature or clay content. The low concentrations of Magnesium in both raw materials can

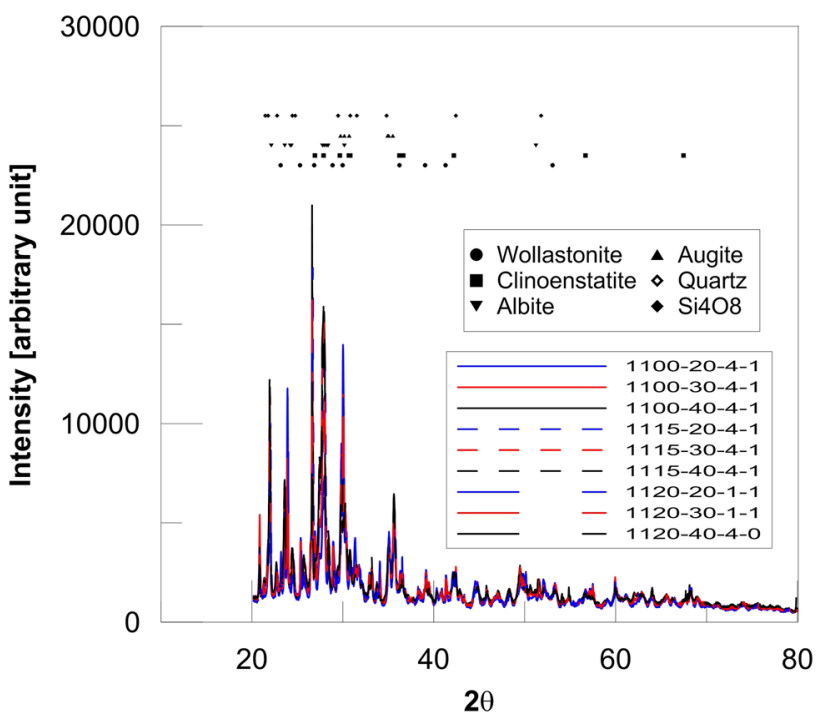

Fig. 10 XRD diffractograms of the samples, superposed, from $2 \theta=20^{\circ}$ to $2 \theta=80^{\circ}$

be considered as a limit for these phases' development. Wollastonite and Albite proportions varied in wider proportions, with overall increasing presence of Albite for highest clay content in mix, and decreasing presence of Wollastonite for highest clay content. The fact that the melting temperature of Albite is given at around $1115^{\circ} \mathrm{C}$ [33] implies that some viscous Albite could react with other phases, or did not completely crystallize, leading to under-estimation on XRD quantification. It is possible that 
Table 5 Relative proportions of the different phases, for 9 samples

\begin{tabular}{llllll}
\hline Sample ID & $\begin{array}{l}\text { Wol- } \\
\text { lastonite } \\
(\%)\end{array}$ & $\begin{array}{l}\text { Quartz } \\
(\%)\end{array}$ & Albite (\%) & $\begin{array}{l}\text { Clinoen- } \\
\text { statite } \\
(\%)\end{array}$ & Augite (\%) \\
\hline $\begin{array}{c}1100-20- \\
4-1\end{array}$ & 38 & 15 & 19 & 12 & 17 \\
$\begin{array}{c}1115-20- \\
4-1\end{array}$ & 21 & 9 & 39 & 13 & 13 \\
$\begin{array}{c}1120-20- \\
1-1\end{array}$ & 29 & 15 & 25 & 15 & 16 \\
$\begin{array}{c}1100-30- \\
4-1\end{array}$ & 20 & 14 & 37 & 14 & $15 \%$ \\
$\begin{array}{c}1115-30- \\
4-1\end{array}$ & 19 & 15 & 35 & 14 & 18 \\
$\begin{array}{c}1120-30- \\
1-1\end{array}$ & 29 & 13 & 26 & 16 & 16 \\
$\begin{array}{c}1100-40- \\
4-0\end{array}$ & 18 & 17 & 37 & 14 & 13 \\
$\begin{array}{c}1115-40- \\
4-0\end{array}$ & 19 & 17 & 33 & 14 & 17 \\
$\begin{array}{l}1120-40- \\
4-0\end{array}$ & 17 & 10 & 40 & 15 & 18 \\
\hline
\end{tabular}

Wollastonite and Albite are competing for Quartz, as $\mathrm{SiO}_{2}$ and $\mathrm{Si}_{4} \mathrm{O}_{8}$ are precursors for these two phases, with Albite being the main driver of the sintering process.

\section{Discussion}

\section{Comparison to a Reference Material: Alumina}

Alumina can be considered as a reference for thermal storage applications, due to its high density, high specific heat as well as its high thermal conductivity [34]. Hence, we compared the specific heat and thermal capacity of alumina and several samples of MWIBA ceramics (Fig. 11). The impact of the supposed mineral transformation on the value of specific heat is very noticeable, and occurs for all samples, although it is less important for the 1120-30 sample. This variation of the specific heat around $900{ }^{\circ} \mathrm{C}$, combined with overall lower specific heat and severely lower density lead to a significant gap in terms of volumetric specific heat between MWIBA ceramics and alumina.

This phenomenon should be investigated further, as there is no mention in the scientific littérature of what might cause it.

\section{Benefits and Detriments}

These MWIBA ceramics are easy to produce, and do not require rare additives or material. Although the firing temperature is higher than usual for the building bricks industry, it is still in the range of tile firing. Therefore, industrialization at reasonable cost might be feasible. The lower density of these ceramics will limit their relevance as thermal
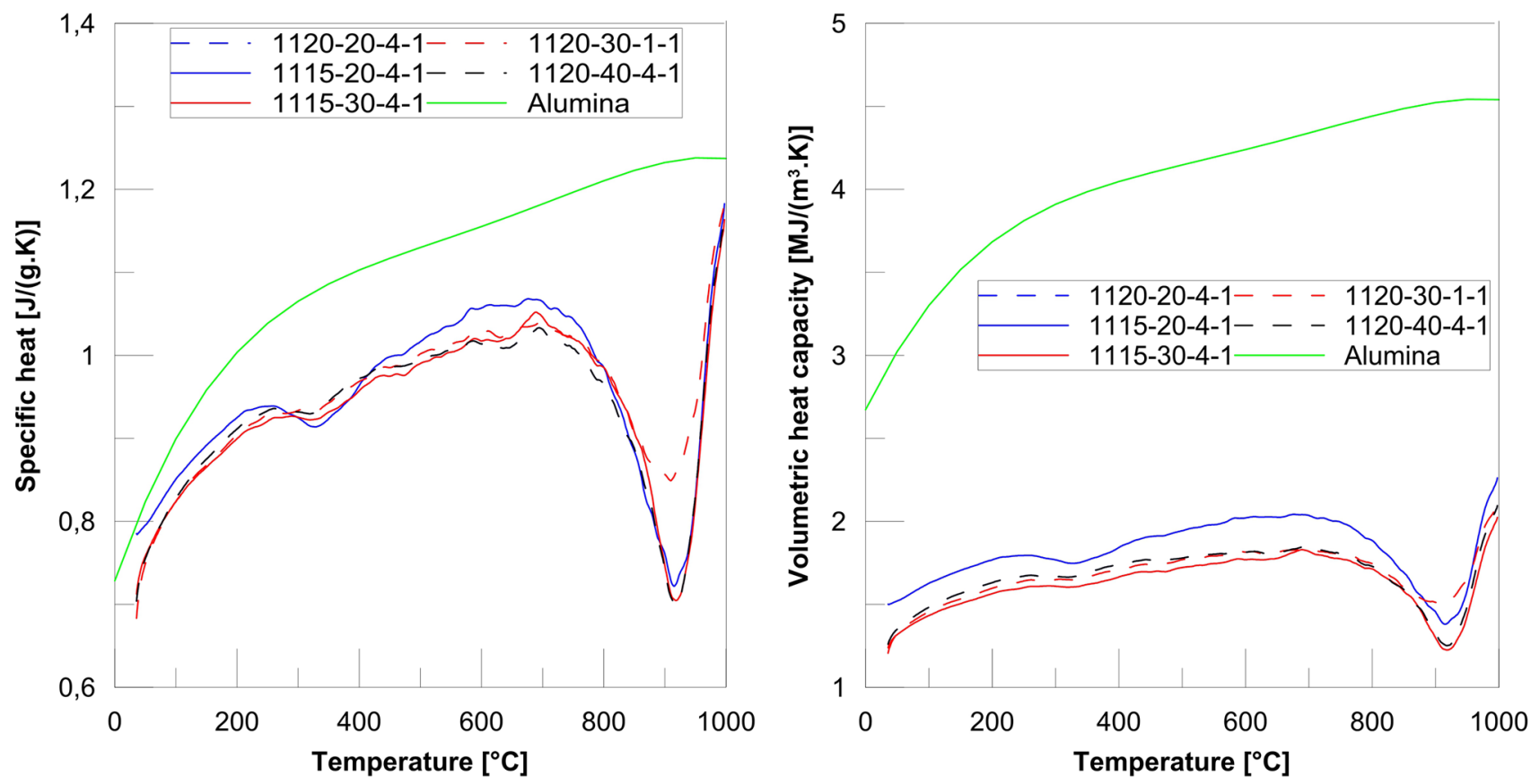

Fig. 11 Specific heat and thermal volumetric capacity of alumina, compared to several samples 
storage media, so further work has to be done to increase this characteristic, while still limiting the use of more complex additives and techniques.

The production costs, as well as the environmental impacts have not been fully quantified to this date, but one can reasonably assume the production cost would be lower than for tiles, due to the low (or even negative) selling price of MWIBA on the market, with transformation processes being similar to those of the building bricks and tiles industries. These ceramics will also have the additional benefit of using byproducts instead of virgin ones, limiting the environmental impacts linked to extraction and purification, especially compared with alumina, for which extraction/ purification process is more complex and requires significant amounts of soda (Bayer process).

The optimal firing temperature has been determined to sit in the range of $1115-1125^{\circ} \mathrm{C}$, and all samples exhibit traces of melting. This temperature is high enough for the material to partially soften or melt, implying viscous flow sintering. Although this might have been beneficial to help filling the porosity of the material, it is a complex phenomenon that also could generate other problems, especially regarding shrinkage and sample deformation.

Shrinkage has not been properly investigated in this work, but it has been noticed that the cylinders tend to creep during firing, with a flattening of their round section, and an overall decrease of their diameter of around $10 \%$. Further work will need to focus on how to limit shrinkage, to ensure minimal deformation of pieces during firing.

\section{Potential for Optimization and Needs for Development}

Although these ceramics are already suitable for thermal energy storage applications, increasing the density of the sintered pieces is critical.

One possible way could be to decrease the particle size of the MWIBA, to increase grains' surface area prior to sintering. Most of the works reported in the literature managed to reach higher densities of the sintered samples (around $2.3-2.5 \mathrm{~g} / \mathrm{cm}^{3}$ or even higher), while firing at lower temperature. But this approach will come into conflict with the goal of limiting production costs and complexity.

Another way might be to mill the MWIBA in order to reach a Funk-Dinger particle size distribution [35-38]. This distribution would allow to increase green bodies compacity, thus might increase sintered density, as well as reduce shrinkage.

It would be also necessary to investigate the presumed phase transformation occurring around $900{ }^{\circ} \mathrm{C}$, to confirm these materials are suitable for use as thermal storage media up to this temperature range.

\section{Potential for Other Fields}

Due to their mechanical properties, these ceramics could be interesting for other applications, especially in the building sector (bricks and tiles), where their moderate density, along with more than average compressive strength, could be relevant. The fact that these ceramics can be produced out of industrial byproducts with conventional methods in the building industry calls for more work on this material, focused on the industrialization potential and industrial relevance of these materials.

However, these applications will require more work regarding the decrease of shrinkage ratio during firing, to ensure minimal deformation of the material. Frost resistance, as well as leaching behavior of the ceramics, should be investigated before concluding about the relevance of this material for building purposes.

\section{Conclusions and Perspectives}

The feasibility of producing cylindrical pellets through extrusion of a plastic paste based on MWIBA and wasted clay is validated, using gross milling of the MWIBA and as-received clay powder. The viscous flow sintering ends up to high enough compressive strength. The samples did not show any significant modification of their behavior when cycled from 25 to $1000{ }^{\circ} \mathrm{C}$. Thus, they can potentially be used as materials for sensible heat storage at high temperature.

The fired density of the samples is limited by high porosity, whether is it open or closed. The proximity of firing temperature and melting temperature end up to the formation of liquid phases, which could exit the sample during sintering and/or expand during firing process, forming wide macroscopic pores (black bodies). Increasing the dwell duration during firing might increase density, if the remaining porosity is due to insufficient mobility of the viscous phase.

These ceramics have been designed to be relatively easy to mass-produce. However, their low density limits their volumetric thermal capacity. This could be addressed by decreasing the particle size of the MWIBA, or mixing batches of different particle size to approach a Funk particle distribution, susceptible to increase the green body compacity and reduce shrinkage [39].

The relatively low thermal capacity of these ceramics can be a barrier for using as thermocline filler material, for prolonged standby period. However, they can still be effective to use the thermocline storage as regenerative devices, in which thermal capacity is of secondary concern, beneath the capabilities in term of heat transfer, for which samples with higher open porosity could be an advantage. 
These ceramics, although exhibiting moderate properties regarding their potential as thermal energy storage media, exhibit desired traits for the building sector, especially regarding compressive strength, coupled with moderate density and limited thermal conductivity. To investigate their potential further in this field, it would be required to evaluate their leaching behavior, as well as improving the sintering process.

Acknowledgements This work was supported by the Programme "Investissements d'avenir" (Investment for the Future) of the Agence Nationale de la Recherche (National Agency for Research) of the French State under Award Number ANR-10-LABX-22-01-SOLSTICE. The author would also like to thank Eco-Tech Ceram for their scientific, material and financial support and the laboratory SPCTS CNRS UMR 7315 for their support.

\section{References}

1. Bethanis, S., Cheeseman, C.R., Sollars, C.J.: Properties and microstructure of sintered incinerator bottom ash. Ceram. Int. 28, 881-886 (2002). https://doi.org/10.1016/S0272-8842(02)00068-8

2. Cheeseman, C.R., Makinde, A., Bethanis, S.: Properties of lightweight aggregate produced by rapid sintering of incinerator bottom ash. Resour. Conserv. Recycl. 43, 147-162 (2005). https:// doi.org/10.1016/j.resconrec.2004.05.004

3. Bourtsalas, A., Vandeperre, L.J., Grimes, S.M., Themelis, N., Cheeseman, C.R.: Production of pyroxene ceramics from the fine fraction of incinerator bottom ash. Waste Manag. 45, 217-225 (2014). https://doi.org/10.1016/j.wasman.2015.02.016

4. Taurino, R., Karamanov, A., Rosa, R., Karamanova, E., Barbieri, L., Atanasova-vladimirova, S., et al.: New ceramic materials from MSWI bottom ash obtained by an innovative microwave-assisted sintering process. J. Eur. Ceram. Soc. 37, 323-331 (2017). https ://doi.org/10.1016/j.jeurceramsoc.2016.08.011

5. Schabbach, L.M., Andreola, F., Karamanova, E., Lancellotti, I., Karamanov, A., Barbieri, L.: Integrated approach to establish the sinter-crystallization ability of glasses from secondary raw material. J. Non Cryst. Solids. 357, 10-17 (2011). https://doi. org/10.1016/j.jnoncrysol.2010.10.006

6. Barbieri, L., Karamanov, A., Corradi, A., Lancellotti, I., Pelino, M., Rincon, J.M.: Structure, chemical durability and crystallization behavior of incinerator-based glassy systems. J. Non Cryst. Solids 354, 521-528 (2008). https://doi.org/10.1016/j.jnoncrysol .2007 .07 .080

7. Py, X., Calvet, N., Olives, R., Meffre, A., Echegut, P., Bessada, C., et al.: Recycled material for sensible heat based thermal energy storage to be used in concentrated solar thermal power plants. J. Sol. Energy Eng. 133, 031008 (2011). https://doi. org/10.1115/1.4004267

8. Kere, A., Dejean, G., Sadiki, N., Olives, R., Goetz, V., Py, X., et al.: Vitrified Industrial wastes as thermal energy storage materials for high temperature applications, in: Int. Conf. Eng. Waste Biomass Valoris, Porto, 2012

9. Py, X., Olives, R., Goetz, V., Falcoz, Q., Meffre, A., Kere, A., et al.: Stockage de l' énergie: énergie thermique, stockage thermique haute température, (n.d.)

10. Crillesen, K., Skaarup, J., Bojsen, K., et al.: International Solid Waste Association: Management of bottom ash from WTE plants-an overview of management options and treatment methods. ISWA, (2006). https://www.iswa.org/uploads/tx_iswaknowle dgebase/Bottom_ash_from_WTE_2006_01.pdf
11. Cavaud, D., Coléou, Z., Guggemos, F., Reynaud, D.: Chiffres clés des énergies renouvelables-Edition 2016, Ministère de l'environnement, 2017. https://www.statistiques.developpem ent-durable.gouv.fr/chiffres-cles-desenergies-renouvelablesedition-2016

12. International Solid Waste Association: Waste-to-Energy Stateof-the-Art-Report. International Solid Waste Association, Copenhagen (2012)

13. Vu, D.H., Wang, K.-S., Chen, J.-H., Nam, B.X., Bac, B.H.: Glass-ceramic from mixtures of bottom ash and fly ash. Waste Manag. 32, 2306-2314 (2012). https://doi.org/10.1016/j.wasma n.2012.05.040

14. Aloisi, M., Karamanov, A., Taglieri, G., Ferrante, F., Pelino, M.: Sintered glass ceramic composites from vitrified municipal solid waste bottom ashes. J. Hazard. Mater. 137, 138-143 (2006). https://doi.org/10.1016/j.jhazmat.2005.12.056

15. Appendino, P., Ferraris, M., Matekovits, I., Salvo, M.: Production of glass-ceramic bodies from the bottom ashes of municipal solid waste incinerators. J. Eur. Ceram. Soc. 24, 803-810 (2004). https://doi.org/10.1016/S0955-2219(03)00264-4

16. Barbieri, L., Corradi, A., Lancellotti, I.: Bulk and sintered glassceramics by recycling municipal incinerator bottom ash. J. Eur. Ceram. Soc. 20, 1637-1643 (2000). https://doi.org/10.1016/ S0955-2219(00)00032-7

17. Acceptabilité environnementale de matériaux alternatifs en technique routière-Les mâchefers d'incinération de déchets non dangereux (MIDND), Sétra, Ministère de l'Ecologie, 2006. http://www.valenseine.com/wp-content/uploads/2018/03/Guide -SETRA-officiel-Oct-2012.pdf

18. Rambaldi, E., Esposito, L., Andreola, F., Barbieri, L., Lancellotti, I., Vassura, I.: The recycling of MSWI bottom ash in silicate based ceramic. Ceram. Int. 36, 2469-2476 (2010). https:// doi.org/10.1016/j.ceramint.2010.08.005

19. Lopez Ferber, N., Falcoz, Q., Minh, D.P., Hoffmann, J.F., Meffre, A., Nzihou, A., et al.: Flexibility and robustness of a high-temperature air/ceramic thermocline heat storage pilot. J. Energy Storage 21, 393-404 (2019). https://doi.org/10.1016/j. est.2018.11.034

20. Dejean, G.: Valorisation de laitiers sidérurgiques comme matériaux de stockage thermique pour procédés énergétiques durables. Application au CSP et au CAES, UPVD, 2014

21. Kere, A., Sadiki, N., Py, X., Goetz, V.: Applicability of thermal energy storage recycled ceramics to high temperature and compressed air operating conditions. Energy Convers. Manag. 88, 113-119 (2014). https://doi.org/10.1016/j.enconman.2014.08.008

22. European Commission, Document de référence sur les meilleures techniques disponibles-Fabrication des céramiques (2007)

23. Taurino, R., Karamanova, E., Barbieri, L., Atanasova-vladimirova, S., Andreola, F., Karamanov, A.: New fired bricks based on municipal solid waste incinerator bottom ash. Waste Manag. Res. 35, 1055-1063 (2017). https://doi.org/10.1177/0734242X1772134 3

24. Zavattoni, S.A.A., Barbato, M.C.C., Pedretti, A., Zanganeh, G., Steinfeld, A.: High temperature rock-bed TES system suitable for industrial-scale CSP Plant-CFD analysis under charge/discharge cyclic conditions. Energy Procedia 46, 124-133 (2014). https:// doi.org/10.1016/j.egypro.2014.01.165

25. IUPAC, Compendium of Chemical Terminology_Gold Book. IUPAC, Research Triangle Park (2014)

26. Becquart, F., Bernard, F., Abriak, N.E., Zentar, R.: Monotonic aspects of the mechanical behaviour of bottom ash from municipal solid waste incineration and its potential use for road construction. Waste Manag. 29, 1320-1329 (2009). https://doi.org/10.1016/j. wasman.2008.08.019

27. Rahaman, M.N.: Ceramic Processing, 2nd edn. CRC Press, Boca Raton (2017) 
28. Cheeseman, C.R., Monteiro Da Rocha, S., Sollars, C., Bethanis, S., Boccaccini, A.R.: Ceramic processing of incinerator bottom ash. Waste Manag. 23, 907-916 (2003). https://doi.org/10.1016/ S0956-053X(03)00039-4

29. Schabbach, L.M., Andreola, F., Barbieri, L., Lancellotti, I., Karamanova, E., Ranguelov, B., et al.: Post-treated incinerator bottom ash as alternative raw material for ceramic manufacturing. J. Eur. Ceram. Soc. 32, 2843-2852 (2012). https://doi.org/10.1016/j.jeurc eramsoc.2012.01.020

30. Techniques de l'ingénieur, Frittage: aspects physico-chimiques Partie 1: frittage en phase solide, 2005. http://www.techniques -ingenieur.fr/base-documentaire/sciences-fondamentales-th8/ fondamentaux-en-chimie-42106210/frittage-aspects-physicochimiques-af6620/

31. Kato, T., Ohashi, K., Fuji, M., Takahashi, M.: Water absorption and retention of porous ceramics fabricated by waste resources, J. Ceram. Soc. Jpn. 116(1350), 212-215 (2008)

32. Vichaphund, S., Thavorniti, P.: Properties of ceramic produced from clay and MSW incineration bottom ash mixtures. Sci. Technol. Asia 15, 89-93 (2010)

33. Anovitz, L.M., Blencoe, J.G.: Dry melting of high albite. Am. Mineral. 84, 1830-1842 (1999). https://doi.org/10.2138/ am-1999-11-1210
34. Auerkari, P.: Mechanical and physical properties of engineering alumina ceramics. Tech. Res. Cent. Finl. 1792, 26 (1996)

35. Funk, J.E., Dinger, D.R.: Predictive Process Control of Crowded Particulate Suspensions-Applied to Ceramic Manufacturing. Springer, New York (1994)

36. Fennis, S.A.A.M., Walraven, J.C.: Using particle packing technology for sustainable concrete mixture design. Heron 57, 73-102 (2012)

37. Shi, C., Wu, Z., Lv, K., Wu, L.: A review on mixture design methods for self-compacting concrete. Constr. Build. Mater. 84, 387398 (2015). https://doi.org/10.1016/j.conbuildmat.2015.03.079

38. Zheng, J., Johnson, P.F., Reed, J.S.: Improved equation of the continuous particle size distribution for dense packing, J. Am. Ceram. Soc. 73(5), 1392-1398 (1990)

39. Kalpakli, Y.K.: Effects of particle size distribution on the refractory properties and corrosion mechanism of ultra-low cement castables. Arch. Mater. Sci. Eng. 34, 81-88 (2008) 